\title{
Brucellosis - Risk Factors and Prevalence: A Review
}

\author{
L.B. Lopes ${ }^{1}$, R. Nicolino ${ }^{2}$ and J.P.A. Haddad ${ }^{*}, 2$ \\ ${ }^{I}$ Instituto Nacional em Ciência e Tecnologia - Informação Genético-Sanitária da Pecuária Brasileira (INCTIGSPB), \\ Brazil \\ ${ }^{2}$ Universidade Federal de Minas Gerais (UFMG), Brazil
}

\begin{abstract}
Brucella is one of the major zoonotic pathogens worldwide, and it is responsible for enormous economic losses as well as considerable human morbidity in endemic areas. The organism infects animals such as swine, cattle, goat, sheep, and dogs. Humans can become infected indirectly through contact with infected animals or by animal products consumption. Brucellosis occurs worldwide, but it is well controlled in most developed countries. The disease is rare in industrialized nations because of routine screening of domestic livestock and animal vaccination programmes. Clinical disease is still common in the Middle East, Asia, Africa, South and Central America, the Mediterranean Basin, and the Caribbean. This review article aims to describe the prevalence of brucellosis in some countries where data are available around different regions of world, and risk factors associated infections according regression models.
\end{abstract}

Keywords: Brucelosis, epidemiology, risk factors, prevalence, Brucella abortous, Brucella melitensis, Brucella ovis, Brucella suis, Brucella canis, review.

\section{INTRODUCTION}

According to the Food and Agriculture Organization (FAO), the World Health Organization (WHO) and the Office International des Epizooties (OIE), brucellosis is still one of the most important and widespread zoonoses in the world. Infections are caused by various bacteria of the genus Brucella, which tend to infect a specific animal species. However, most species of Brucella are able to infect other animal species as well and some of them have zoonotic potential [1]. In humans, brucellosis can be caused by $B$. abortus, B. melitensis, B. suis biovars 1-4 and, rarely, $B$. canis or marine mammal Brucella. B. ovis, B. neotomae, and $B$. suis biovar 5 have not been associated with human disease.

The disease affects cattle, swine, sheep and goats, camels, equines, and dogs. It may also infect other ruminants and marine mammals. The disease in animals is characterized by abortions or reproductive failure. While animals typically recover, and will be able to have live offspring following the initial abortion, they may continue to shed the bacteria. Brucellosis in cattle (B. abortus) in sheep and goats (B. melitensis) and in swine (B. suis) are diseases listed in the World Organization for Animal Health (OIE) Terrestrial Animal Health Code [2].

The classical names related to the six Brucella species are validly published in the Approved Lists of Bacterial Names, 1980, and the designated type strains are attached to these validly published names: $B$. abortus, $B$. melitensis, $B$. suis, B. neotomae, B. ovis, and B. canis. The first three of

*Address correspondence to this author at the Universidade Federal de Minas Gerais (UFMG) and member of Instituto Nacional em Ciencia e Tecnologia - Informacao Genetico Sanitaria da Pecuaria Brasileira (INCTIGSPB), Brazil; Tel: +55 313409 2125; Fax: +55 313409 2080;

E-mail: jphaddad@globo.com these are subdivided into biovars based on cultural and serological properties. Strains of Brucella have been isolated in the last decade from marine mammals that cannot be ascribed to any of the above-recognized species. Investigations are currently underway to establish their correct position in the taxonomy, and it has been proposed that they could be classified into two new species, $B$. ceti and B. pinnipedialis [3]. A new strain, named Brucella microti, was recently isolated from the common vole (Microtus arvalis) in Central Europe [4]. Finally, Brucella shows close genetic relatedness to some plant pathogens and symbionts of the genera Agrobacterium and Rhizobium, as well as, animal pathogens (Bartonella) and opportunistic or soil bacteria (Ochrobactrum).

Brucellosis occurs worldwide but it is well controlled in most developed countries. The disease is rare in industrialized nations because of routine screening of domestic livestock and animal vaccination programmes [5, 6]. Clinical disease is still common in the Middle East, Asia, Africa, South and Central America, the Mediterranean Basin and the Caribbean. Additional losses result from human infection with its prolonged misery, debility and generalized aching, which may last for months or years [7, 8]. Sheep and goats and their products are the main sources of infection. Consequently, brucellosis has been an occupational risk for farmers, veterinary surgeons and employees in the meatpacking business [1]. Non-occupational sources of infection include consumption of fresh, unpasteurized goat cheese and raw fresh (untreated) milk [9].

\section{ETIOLOGY AND SPATIAL DISTRIBUTION}

\section{Brucella Abortus}

Brucellosis in cattle is usually caused by biovars of $B$. abortus. In some countries, particularly in southern Europe and western Asia, where cattle are kept in close association with sheep or goats, infection can also be caused by $B$. 
melitensis $[10,11]$. Occasionally, $B$. suis may cause a chronic infection in the mammary gland of cattle, but it has not been reported to cause abortion or spread to other animals [12]. In cattle, B. abortus causes abortions, stillbirths and weak calves; abortions usually occur during the second half of gestation. The placenta may be retained and lactation may be decreased. After the first abortion, subsequent pregnancies are generally normal; however, cows may shed the organism in milk and uterine discharges. Epididymitis, seminal vesiculitis, orchitis and testicular abscesses are sometimes seen in bulls.

Brucellosis is readily transmissible to humans, causing acute febrile illness - undulant fever - which may progress to a more chronic form and can also produce serious complications affecting the muscle-skeletal, cardiovascular, and central nervous systems. Infection is often due to occupational exposure and is essentially acquired by the oral, respiratory, or conjunctival routes, but ingestion of dairy products constitutes the main risk to the general public where the disease is endemic. There is an occupational risk to veterinarians and farmers who handle infected animals and aborted fetuses or placentas.

\section{North America}

Efforts to eradicate brucellosis caused by B. abortus in the United States began in 1934 as part of an economic recovery program to reduce the cattle population because of the Great Depression. A number of States saw this as an opportunity to reduce the level of brucellosis, which was the most significant livestock disease problem in the US at the time. In 1934 and 1935, the reactor rate in adult cattle tested was $11.5 \%$. In 1954, the magnitude of the brucellosis problem in terms of economics to the cattle industry and human health prompted the United States Congress to appropriate funds for a comprehensive national effort to eradicate brucellosis. A major factor in the success of the program was the acceptance of eradication program procedures by livestock owners in spite of the inconvenience, cost, and additional work required. During the year 1957, shortly after the inception of the program, there were almost 124,000 infected herds disclosed. It is estimated that this was only one-third to on half of what actually existed at the time, since surveillance activities at the time were not at an optimal level [13].

In the mid-1970s, blood testing of cattle at the first place they were assembled (livestock markets and stockyards) was initiated in all high incidence states. This provided for the identification of reactor and exposed animals before they were moved to other herds or areas. Depopulation of affected herds was also adopted in the mid-1970s as an additional management option that provided a solution for intractable and heavily affected herds. Depopulation has been especially important in the last several years, as the number of affected herds has decreased rapidly [13].

In the 1990s, a low number of newly affected herds continued to be disclosed every year. Consequently, in 1997, the Brucellosis Emergency Action Plan (BEAP) was implemented. According to the plan, all activities involving brucellosis surveillance and management of new cases were to be conducted as an emergency action. This means that all activities associated with each new case would be dealt with as a top priority. The plan emphasized depopulation of affected herds, enhanced surveillance, epidemiology and herd management, and rapid response. In the year, this plan was implemented, there were 85 cumulative affected herds in the US [13].

In December 31st, 2000, there were no affected cattle herds in the United States. This was the first time in the history of the brucellosis program that the United States had no known brucellosis affected herds [13]. However, brucellosis has a variable, sometimes quite lengthy incubation period, so it is expected that additional affected herds will be disclosed. Enhanced surveillance efforts have been maintained to ensure the detection of the last remaining affected herds as soon as possible. Indeed, three more affected herds were disclosed during fiscal year 2001, one each in Arkansas, Kansas, and Missouri. Those herds were rapidly depopulated, and the nation again had zero brucellosis affected herds as of November 30, 2001 [13].

For the first time in the 74-year history of the Brucellosis program, all 50 States, Puerto Rico, and the U.S. Virgin Islands were simultaneously designated brucellosis Class Free for a brief period of time in fiscal year (FY) 2008. This milestone occurred when Texas was declared brucellosis free on February 1st, 2008. However, in May 2008, the State of Montana reported a second brucellosis affected cattle herd within a twenty-four month period of time, resulting in reclassification to brucellosis Class A State status on September 3, 2008. In June 30, 2008, APHIS confirmed $B$. abortus in two cows originating from a cattle herd in Sublette County, Wyoming. These animals were tested as part of Wyoming's first-point testing at livestock auction markets [13]. The brucellosis affected herd was subsequently depopulated with indemnity and a thorough epidemiologic investigation conducted. No additional brucellosis affected cattle herds have been disclosed. Infected free-ranging elk are thought to be the most likely source of infection. The reclassification of Montana to Class A State status in FY 2008 demonstrates the importance of remaining vigilant. The presence of brucellosis in free-ranging bison and elk in the GYA threatens the brucellosis status of the surrounding States and the health of their livestock herds. As a result, final eradication of brucellosis from the United States continues to be a challenge [14]. Seroprevalence of brucellosis in the Yellowstone National Park bison is approximately $50 \%$ in the $B$. abortus can be isolated from approximately $46 \%$ of seropositive bisons. Bulls have a high seroprevalence for brucellosis, and recent data have suggested that behavior may play a role in the transmission to males. Experimental studies have demonstrated that bisons can transmit $B$. abortus to co-housed cattle, although documentation of transmission under field conditions is lacking [15].

The Bayesian Monte Carlo method, used in some studies, links process model inputs to observed surveillance results via Bayes Theorem. The surveillance evidence across multiple years is accumulated at a discounted rate based on the probability of introducing new infections into a given area. The process model's inputs include herd size, culling rate per herd, within-herd prevalence, serologic test performance, and the probability of successfully investigating positive results. The surveillance results 
comprise the number of cows and bulls tested at slaughter and the number of affected herds detected each year. The results find at least $95 \%$ confidence that brucellosis herd prevalence among beef cow-calf herds is less than $0.014 \%$ ( 3 per 21,500 herds) and $0.00081 \%$ (5 per $6,15,770)$ after 5 years of slaughter surveillance (with no detections of affected herds) in a typical U.S. state and across 46 low-risk U.S. states, respectively. These results were based on conservative modeling assumptions, but sensitivity analysis suggests only slight changes in the results from changing the assumed process model input values [16].

The Canadian national cattle herd was declared brucellosis-free on September 19, 1985. Currently, brucellosis monitoring continues in the form of active disease surveillance through auction market testing in Northern Alberta and British Columbia, and in the form of passive surveillance through disease reporting mechanisms and the brucellosis testing of cattle being qualified for export to countries other than the United States. Brucellosis ring testing of milk and cream, as well as the Market Cow Testing of slaughter cattle, ended on April 1, 1999.

In Mexico, brucellosis is still one of the most important bacterial diseases. The significance of brucellosis is seen in obvious production losses resulting from the clinical disease in livestock, restrictions applied to infected animals and their products in local agricultural and global markets [17]. Although good progress has been made in many areas, brucellosis is still present in cattle, goats, sheep and probably swine [18]. Five of the seven known Brucella species have been isolated; only $B$. neotomae have not been isolated. These include $B$. melitensis biovars $1-3 ; B$. abortus biovars $1,2,4-6 ; B$. suis biovar $1 ; B$. canis and B. ovis. Some of the isolations have been made in non-traditional target animal species; for example, one strain of $B$. suis was isolated from dairy cow cheese and some $B$. melitensis strains have been isolated from dairy cow milk [19]. It appears that animal to animal contact favors the spread of the disease. Brucellosis in cattle is caused almost exclusively by B. abortus. There are some areas where the co-existence of cattle and small ruminants facilitate cattle infection with B. melitensis [20].

\section{Central America}

Central America (CA) is composed by Guatemala, Belize, Honduras, El Salvador, Nicaragua, Costa Rica and Panamá. With the exception of Costa Rica and Panamá, where conditions are less dramatic, the other CA countries struggle against poor budgets and limited laboratory facilities for the diagnosis and control of infectious diseases. Consequently, investigations on brucellosis in CA are discontinuous and not rigorously systematic. The published materials related to this topic are scarce, being the principal sources the yearly reports of Animal and Health Ministries and of the Veterinary Schools [21].

B. abortus biotype 1 and 2 are the only identified biotypes in $\mathrm{CA}$ and the most common isolated strains, mainly in bovines, humans and sporadically in dogs and horses. B. suis has been isolated from swine and humans in all CA countries. B. melitensis has been isolated from sheep and humans in Guatemala and suspected in Panamá. B. canis has been isolated from dogs in Costa Rica. Surveys of $80 \%$ of the ovine and caprine populations in El Salvador and
Costa Rica did not reveal antibodies against Brucella, suggesting the absence of $B$. melitensis in these countries. Restricted surveys have failed to reveal antibodies against Brucella in wild mammals [21].

Based on limited serological surveys performed during the last 10 years, the estimated prevalence of bovine brucellosis in CA corresponds from 4 to $8 \%$, and a rate of herd infection (mainly dairy herds) is from 10 to $25 \%$. El Salvador seems to be the country with less bovine brucellosis (close to $1 \%$ prevalence), while Guatemala and Costa Rica seems to possess the highest prevalence; although, this may be the result of more efficient diagnosis performed in these countries. Most of the infected bovines are concentrated in the pre-mountain and high lands, were dairy herds are located. Even though the number of bovines per herd is larger in farms located in the lowlands, the Brucella infection prevalence is moderate. It is known that the risk for transmission is reduced in extensive type of management where lower density of bovines exists and the life span of these animals is shorter. In contrast, the intensive type of management that favors close contacts between bovines and therefore the chance of Brucella transmission may explain the higher prevalence in dairy herds. Generally, male bovines show higher level of infection than females, probably reflecting differences in vaccination rates. No data is available on the prevalence of Brucella infection in pigs, goats, sheep and dogs. One survey carried out in 1996 by the Veterinary School in the three major swine farms in Costa Rica did not reveal the presence of antibodies against Brucella [21].

\section{South America}

In Venezuela, brucellosis still as an important disease. Since its discovery in 1930, several control and eradication measures have been established. But to date, the disease continues to produce large economic losses, especially in cattle, and constitutes a serious public health problem [22]. The most prevalent specie in the country is B. abortus. It has been identified as the causative pathogen of brucellosis in humans and animals. B. suis has been identified as causing abortions in some swine herds in the center of the country. $B$. melitensis has been isolated but scarcely studied and its impact in animal and human health is not very well known [23]. Other Brucella spp. have not been identified in the country and the disease has been hardly studied in wild animals. The official published reports of positive animals as determined with the plate agglutination test show a low rate. But results obtained with other tests of high sensitivity and specificity such as the ELISA indicate a prevalence of approximately $10.5 \%$. This prevalence is even higher in some areas of the country where the disease produces serious disease in cattle, buffaloes, and humans [24].

The region of Los Lagos, situated in Chile, is known for its milk production and contains most of the dairy farms in the country. It contains $34 \%$ of the national bovine population and produces $65 \%$ of the country's annual milk production [25]. Historically, it has also presented a high rate of $B$. abortus infection in its herds. In the national study of bovine brucellosis prevalence carried out in 1991, the herd rates ranged from 23 to $38 \%$. In the year 2001 , the rate of Milk Ring Test (MRT) positive dairies reached 19.7\%, while 
in the year 1996 this rate was about $46 \%$. The reduction of this rate to less than half of that observed in 1996 was due to the switch from vaccine strain 19 to strain RB51 and to the clean-up of brucellosis infected herds. The initial reactor rate according Rose Bengal Test in 1998 was $8.52 \%$. In 1999, the annual reactor rate was $8.9 \%, 5.94 \%$ in 2000 and $5.53 \%$ in 2001. In the years 2000 and 2001, the number of herds cleaned up has been higher than those declared infected. Therefore, the herd prevalence began to decrease from the year 2000 onwards [26].

In Paraguay, the disease has has been recognized in the country for several years. Though most studies and reports are on B. abortus in cattle, B. melitensis, and B. suis were also isolated and identified. During the last decades, the number of individual animal reactors remains around 3-4\%, while a reduction of reactors through the years, increasing the number of negative groups from $33.1 \%$ in 1979 to $92.1 \%$ in 2000. Conversely, the number of suspects was reduced from 32.5 to $1.4 \%$ during the same period, 1979 up to 2000 , reflecting a better disease management and possibly an improved general education and handling of information on immune status of the animals, and testing practices [27].

Brucellosis has been known in Argentina since the 19th century. There are many descriptions of the disease that confirm the presence of animal brucellosis in Argentine herds. The first report of an isolation of a B. abortus strain from a milk of a cow was done in 1925 [28]. All surveys done around the middle of the 20th century described a prevalence of $20 \%$ in dairy cattle and $18 \%$ in slaughterhouses. In the middle of the last century, bovine brucellosis has been detected in most of the Argentine provinces. The individual prevalence for dairy cattle in the country was estimated between 2 and $2.5 \%$. Most of the isolates correspond to $B$. abortus biovar 1 , however, $B$. abortus biovar 2 is also found. Previously, B. suis could also be isolated from cattle produced by small producers in suburban areas of the countries due to common practice of raising cattle and swine in close contact. Recently, the first isolation of B. abortus biovar 1 from buffalo was reported in the northeast of the country [29].

\section{Spatial Distribution in Brazil and Risk Factors Associated}

In 2001, the Brazilian Ministry of Agriculture, Livestock, and Food Supply (MAPA) started a new National Program for the Control and Eradication of Brucellosis and Tuberculosis (NPCEBT). MAPA established a collaborative project with the Universidade de São Paulo (USP), which also included the Universidade de Brasilia (UnB). So far, 15 states completed the survey, and the results are described below [30].

\section{Federal District of Brazil}

A total of 2,019 serum samples from 278 herds were collected. In each herd, it was applied an epidemiological questionnaire focused on herd traits as well as husbandry and sanitary practices that could be associated with the risk of infection. The serum samples were screened for antibodies against Brucella spp. by the Rose-Bengal Test (RBT), and all positive sera were re-tested by the 2 - mercaptoethanol test (2-ME). The herd was considered positive if at least one animal was positive on both RBT and 2-ME tests. Herd prevalence was estimated as $2.5 \%[1.0-5.1 \%]$ whereas animal prevalence was $0.16 \%$ [0.04-0.28\%] [31].

\section{State of Espírito Santo}

The State was divided in two regions. Three hundred herds were randomly sampled in each region and a preestablished number of animals were sampled in each of these herds. A total of 5,351 serum samples from 622 herds were collected. The prevalence of infected herds and animals in the State were, respectively, 9.0\% [7.0-11.6\%] and 3.5\% [1.9-6.4\%]. The prevalence of infected herds and animals in the regions were, respectively: region $1,6.8 \%$ [4.5-10.2\%] and $3.4 \%$ [1.3-8.6\%]; and region 2, 10.9\% [7.9-14.8\%] and $3.7 \%$ [2.1-6.3\%]. The risk factors (odds ratio, OR) associated with the presence of the infection were: use of artificial insemination $(\mathrm{OR}=7.05$ [2.51-19.82]) and intensive/semi-intensive management systems $(\mathrm{OR}=2.98$ [1.22-7.26]). Vaccination of heifers from three to eight months of age was a protective factor $(\mathrm{OR}=0.03[0.01-0.1])$ [32].

\section{State of Goiás}

The State was divided in three regions. Three hundred herds were randomly sampled in each region and a preestablished number of animals were sampled in each of these herds. A total of 10,744 serum samples from 900 herds were collected. For region 1, the herd prevalence was 7.7\% [4.7$10.7 \%]$ and the animal prevalence was $1.4 \%$ [0.99-1.7\%]. For region 2, the herd prevalence was $19.5 \%$ [15.0-24.0\%] and the animal prevalence was $2.6 \%$ [2.0-3.1\%]. For region 3 , the herd prevalence was $21.4 \%$ [16.8-26.1\%] and the animal prevalence was $4.3 \%[3.7-5.0 \%]$. For the whole state, the herd prevalence was $17.5 \%$ [14.9-20.2\%] and the animal prevalence was $3.0 \%$ [2.7-3.3\%]. The multivariate analysis identified the following risk factors (odds ratio, OR) associated with positive herds: purchase of breeding stock from cattle traders $(\mathrm{OR}=2.06[1.12-3.52])$, occurrence of abortions over the last 12 months $(\mathrm{OR}=5.83$ [3.86-8.8]), and vaccination against brucellosis $(\mathrm{OR}=2.07$ [1.38-3.09]). Both the abortions and the vaccination are, in this case, a consequence of the herd being infected with brucellosis [33].

\section{State of Mato Grosso}

The State was divided into four productive regions, and 13,684 bovines from 1,152 herds were sampled. The prevalence of infected herds and animals in the State of Mato Grosso were 41.2 percent [38.0-44.4 percent] and 10.2 percent [7.4-13.1 percent], respectively. In the productive regions, the prevalence of infected herds were 36.9 percent [29.2-45.2 percent], 27.2 percent [22.8-32.1 percent], 40.4 percent [38.8-46.2 percent], and 50.3 percent [44.5-56.1 percent], respectively; and the prevalence of infected animals were 7.9 percent [3.0-12.9 percent], 4.1 percent [2.8-5.4 percent], 8.1 percent [5.2-11.1 percent], and 15.3 percent [9.2-21.3 percent], respectively, for regions $1,2,3$, and 4 . The risk factors (odds ratio, OR) associated with the presence of the infection in the State were: beef cattle farming $(\mathrm{OR}=1.8[1.2-2.5])$, mixed (beef and dairy) cattle farming $(\mathrm{OR}=1.8[1.2-2.7])$, farms with 11 to 50 females $(\mathrm{OR}=4.8$ [1.1-20.8]), farms with more than 51 females 
$(\mathrm{OR}=6.8[1.6-29.0])$, and occurrence of abortion $(\mathrm{OR}=1.7$ [1.3-2.2]) [34].

\section{State of Mato Grosso do Sul}

The State was divided in three regions: beef cattle Pantanal, beef cattle Plateau, and dairy cattle Plateau. Herds were randomly sampled in each region and a pre-established number of animals were sampled in each of these herds. A total of 14,849 serum samples from 1,004 herds were collected. The prevalence of infected herds in the State was 41.5 percent [36.5-44.7 percent]. The prevalence of infected herds in the regions were, respectively: 40.6 percent [35.845.5 percent] for beef cattle Plateau, 59.0 percent [52.8-64.9 percent] for beef cattle Pantanal, and 33.1 percent [28.4-38.1 percent] for dairy cattle Plateau. The risk factors (odds ratio, $\mathrm{OR}$ ) associated with the presence of the infection were: herd size larger than 500 cows $(\mathrm{OR}=2.46$ [1.81-3.34]), birth of weak calf $(\mathrm{OR}=1.20[0.87-1.65])$, and use of artificial insemination $(\mathrm{OR}=0.71[0.50-1.01])$ [35].

\section{State of Minas Gerais}

The State was divided in seven regions. Three hundred herds were randomly sampled in each region and a preestablished number of animals were sampled in each of these herds. A total of 20,643 serum samples from 2,204 herds were collected. The prevalence of infected herds and animals in the State were, respectively, 6.0 percent [5.0-7.1 percent] and 1.1 percent [0.78-1.4 percent]. In the productive regions, the prevalence of infected herds and animals were, respectively: regions $1,4.7$ percent [2.7-7.7 percent] and 0.82 percent [0.06-1.6 percent]; region $2,7.2$ percent [4.610.6 percent] and 1.2 percent [0.53-1.8 percent]; region 3 , 6.8 percent [4.3-10.0 percent] and 1.5 percent [0.47-2.4 percent]; region 4, 6.5 percent [4.1-9.8 percent] and 1.1 percent $[0.39-1.7$ percent]; region $5,3.8$ percent $[2.0-6.5$ percent] and 0.40 percent [0.11-0.69 percent]; region $6,6.2$ percent [3.8-9.6 percent] and 0.66 percent [0.29-1.0 percent]; and region $7,11.0$ percent $[7.7-15.0$ percent] and 1.7 percent [0.92-2.6 percent]. The risk factors (odds ratio, OR) associated with positive herds were: purchase of breeding stock $(\mathrm{OR}=1.66$ [1.13-2.44]), occurrence of abortions over the last 12 months $(\mathrm{OR}=1.81$ [1.26-2.60]), and the presence of deer in the farm $(\mathrm{OR}=1.56$ [1.08-2.27]). Vaccination against brucellosis was a protective factor $(\mathrm{OR}=0.38[0.19$ $0.79])$. It can be concluded that the compulsory vaccination [36].

\section{State of Paraná}

In this study, the State was divided into seven regions. Three hundred herds were randomly sampled in each region and a pre-established number of animals were sampled in each of these herds. A total of 1,4857 serum samples from 2,098 herds were collected. The prevalence of infected herds and infected animals in Paraná State were 4.0 percent [3.24.8 percent] and 1.7 percent [1.1-2.4 percent], respectively. In the regions, the prevalence of infected herds and animals were: region $1,14.7$ percent [10.9-19.2 percent] and 2.8 percent [1.2-4.4 percent]; region $2,8.8$ percent [5.9-12.6 percent] and 2.4 percent [1.0-3.8 percent]; region $3,3.4$ percent [1.6-6.1 percent] and 0.85 percent [0.21-1.5 percent]; region $4,2.3$ percent $[0.94-4.8$ percent $]$ and 0.83 percent [0.02-1.6 percent]; region 5, 2.3 percent [0.94-4.7 percent] and 1.7 percent [0.06-3.3 percent]; region $6,0.34$ percent [01.9 percent] and 0.09 percent [ $0-0.27$ percent]; and region 7 , 1.0 percent $[0.21-2.9$ percent $]$ and 2.2 percent $[0-6,0$ percent]. The risk factors (odds ratio, OR) associated with the presence of the infection were: purchase of animals for breeding $(\mathrm{OR}=2.20[1.42-3.40])$ and pasture rental practice $(\mathrm{OR}=2.45$ [1.54-3.90]) [37].

\section{State of Rio Grande do Sul}

The State was divided in seven regions. Three hundred herds were randomly sampled in each region and a preestablished number of animals were sampled in each of these herds. A total of 16,072 serum samples from 1,957 herds, were collected. The prevalence of infected herds and animals in the State were, respectively 2.1 percent [1.5-2.6 percent] and 1.0 percent $[0.60-1.4$ percent]. In the regions, the prevalence of infected herds and animals were, respectively: region $1,3.1$ percent [1.4-5.7 percent] and 0.95 percent [0.02.0 percent]; region $2,7.7$ percent [4.9-11.3 percent] and 1.0 percent $[0.40-1.7$ percent]; region $3,5.7$ percent $[3.4-8.8$ percent] and 2.1 percent [0.41-3.8 percent]; region $4,0.66$ percent [0.08-2.4 percent] and 0.66 percent [0.0-1.8 percent]; region $5,0.66$ percent $[0.08-2.4$ percent $]$ and 0.05 percent [0.0-0.13 percent]; region $6,0.0$ percent $[0.0-1.3$ percent $]$ and 0.0 percent $[0.0-0.25$ percent]; and region $7,5.4$ percent [2.5-10.1 percent] and 2.9 percent [0.49-5.3 percent]. The risk factors (odds ratio, OR) associated with the presence of infection were: beef herd $(\mathrm{OR}=4.27$ [1.82-10.01]) and recent history of abortion $(\mathrm{OR}=3.27-1.71-6.25])[38]$.

\section{State of Bahia}

The State was divided into four similar production regions, 300 herds were randomly sampled in each region, and 10 to 15 adult bovine females were sampled in each of these herds. A total of 10,816 serum samples from 1,413 herds were collected. The prevalence of infected herds and seropositive adult bovine females in Bahia State were: 4.2 percent [3.1-5.3 percent] and 0.66 percent [0.41-0.93 percent], respectively. In the production regions, prevalence of infected herds and animals were, respectively: region 1, 5.8 percent $[3.6-8.7$ percent] and 0.86 percent $[0.41-1.3$ percent]; region 2, 3.1 percent [1.5-5.6 percent] and 1.2 percent [0.25-2.1 percent]; region 3, 6.3 percent [4.0-9.3 percent] and 1.7 percent [0.66-2.7 percent]; and region 4 , 0.60 percent $[0.07-2.2$ percent $]$ and 0.07 percent $[0.00-0.2$ percent]. In each herd, an epidemiological questionnaire was applied. The risk factors (odds ratio, OR) associated with the presence of the infection were: purchase of breeding animals $(\mathrm{OR}=2.27)$ and presence of flood areas $(\mathrm{OR}=1.76)$. Vaccination of heifers from three to eight months of age was a protective factor $(\mathrm{OR}=0.53)$ [39].

\section{State of Tocantins}

State was divided into six regions with a homogeneous productive system. For each region, a simple random sample was calculated to estimate the prevalence both in farms and cows older than two-year. To achieve this, from 10 to 15 adult cows (older than two-year) were sampled. A total of 20,908 sera from 1,842 farms were obtained. For the whole State of Tocantins, the prevalence of positive farms (or farms with at least one positive animal) was 21.2 percent [19.323.1 percent]. When the production regions were considered, 
the prevalence for the regions $1,2,3$, and 5 were: 16.0 percent [12.1-20.6 percent], 37.6 percent [32.1-43.4 percent], 26.4 percent [21.5-31.7 percent], and 29.3 percent [24.3-34.7 percent], respectively. In the regions 4 and 6 , the prevalence were 5.8 percent [3.5-9.1 percent] and 8.6 percent [5.7-12.2 percent], respectively. In each visited farm, a questionnaire was applied, in order to evaluate the association between with possible risk factors and the brucellosis. The risk factors (odds ratio, OR) associated with the infected herds were number of cows above $120(\mathrm{OR}=2.0)$ and slaughtering of breeding animals in the farm $(\mathrm{OR}=1.52)$. Vaccinating against brucellosis $(\mathrm{OR}=0.37)$, presence of birth pen $(\mathrm{OR}=$ $0.72)$, and dairy farm $(\mathrm{OR}=0.63)$ presented as protective factors [40].

\section{State of Sergipe}

The State was divided in two regions. Around three hundred herds were randomly sampled in each region and a pre-established number of animals were sampled in each of these herds. A total of 4,757 serum samples from 590 herds were collected. The prevalence of infected herds and animals in the State were, respectively: 12.6 percent [9.2-16.0 percent] and 3.4 percent [2.3-4.4 percent]. The prevalence of infected herds and animals in the regions were, respectively: region $1,11.1$ percent [7.9-15.0 percent] and 2.6 percent [1.6-3.5 percent]; and region 2, 12.9 percent [9.1-17.6 percent] and 6.2 percent [3.0-9.5 percent]. The risk factors associated with the presence of the infection were: veterinary assistance $(\mathrm{OR}=2.89$ [1.15-7.23]), herd size $\geq 30$ adult females $(\mathrm{OR}=1.88$ [1.07-3.28]), and use of artificial insemination $(\mathrm{OR}=1.92$ [0.84-4.38]) [41].

\section{State of São Paulo}

The state was stratified in seven cattle production regions and 150 herds with reproductive activity were randomly selected within each one. A total of 1,073 herds were sampled. In a second stage, 10 or 15 cows older than 24 month age (in herds with $<100$ cows and herds $\geq 100$ cows, respectively) were bled at random. A total of 8,761 animals were bled. The estimated prevalence of herds with at least one positive animal was 9.7 percent [7.8-11.6 percent], whereas the estimated prevalence of positive cattle was 3.8 percent [0.7-6.9 percent] in São Paulo State. An epidemiological questionnaire was applied in each farm, allowing the evaluation of the association of selected risk factors with the disease. The characteristics associated with the brucellosis infected herds were farms with more than 87 bovines $(\mathrm{OR}=2.25)$ and introduction of breeding cattle $(\mathrm{OR}=1.56)$ [42].

\section{State of Santa Catarina}

The State was divided into five regions. Three hundred herds were randomly sampled in each region and a preestablished number of animals were sampled in each of these herds. A total of 7,801 serum samples from 1,586 herds were collected. The prevalence of infected herds and animals in Santa Catarina State were, respectively: 0.32 percent $[0.10$ 0.69 percent] and 0.06 percent $[0.0-0.17$ percent]. The prevalence of infected herds in the regions were: region 1 , 0.33 percent [0.0-0.99 percent]; region $2,0.33$ percent $[0.0$ 1.0 percent]; region $3,0.25$ percent $[0.0-0.75$ percent $]$; region
4, 0.66 percent [0.08-1.84 percent]; and region 5, 0.33 percent [0.0-1.00 percent] [43].

\section{State of Rondônia}

The State was divided into three regions. Three hundred herds were randomly sampled in each region. A preestablished number of animals were sampled in each of these herds. From 927 herds and 9,717 serum samples were collected. The prevalence of infected herds and animals in Rondônia State were 35.2 percent [32.1-38.4 percent] and 6.2 percent [4.9-7.6 percent], respectively. In the regions, the prevalence of infected herds and animals were, respectively: region $1,41.9$ percent [36.3-47.6 percent] and 8.3 percent [5.9-10.8 percent]; region 2, 31.7 percent [26.5-37.2 percent] and 5.9 percent [4.3-7.6 percent]; and region $3,31.9$ percent [26.7-37.4 percent] and 4.6 percent [2.5-6.6 percent]. The risk factors (odds ratio, OR) associated with the presence of the infection were: recent history of abortion $(\mathrm{OR}=1.42$ [1.04-1.95]) and beef herd (OR=1.75 [1.30-2.38]) [44].

\section{State of Rio de Janeiro}

The State was divided in three regions. Three hundred herds were randomly sampled in each region and a preestablished number of animals were sampled in each herd. A total of 8,239 serum samples from 945 herds were collected. The prevalence of infected herds and animals in the State were, respectively: 15.4 percent [12.9-17.9 percent] and 4.1 percent [2.8-5.3 percent]. The prevalence of infected herds and animals in the regions were, respectively: region $1,13.8$ percent [10.2-18.2 percent] and 3.0 percent [1.9-4.1 percent]; region $2,15.7$ percent [11.9-20.2 percent] and 2.3 percent [1.4-3.2 percent]; and region 3, 19.6 percent [15.4-24.4 percent] and 9.3 percent [4.5-14.1 percent]. The risk factors (odds ratio, OR) associated with the presence of the infection were: herd size larger than 30 cows $(\mathrm{OR}=2.33$ [1.51-3.07]), purchase of animals for breeding $(\mathrm{OR}=1.95[1.13-2.45)$, and pasture rental practice $(\mathrm{R}=1.74$ [1.03-2.74]) [45].

\section{Near East Region}

In the Near East region, animal brucellosis affects almost all domestic animals. In dairy cattle, the disease is a major obstacle to the importation of high producing breeds particularly susceptible to the disease, and represents a significant constraint to the improvement of milk production and cross breeding. B. abortus biovar 1 was reported in Egypt, biovar 2 in Iran, biovar 3 in Iran and Turkey and biovar 6 in Sudan. Little data are available regarding brucellosis in animals in Ethiopia, Somalia, Eritrea, Syria and United Arab Emirates and no data are available on animal brucellosis in Qatar, Bahrain, Chad, Djibouti and Mauritania, though, all countries of the region, with the exception of Bahrain and Qatar, reported brucellosis in animals [46].

The prevalence of brucellosis was investigated in cattle, farmers and veterinarians in the Kars district of Turkey between 2004-2006. In order to achieve this, a total of 407 serum samples of cattle from 27 herds having history of abortions were examined for Brucella antibodies by RBPT and SAT. In addition, the sera collected from 246 farmers (130 males and 116 females) and 28 veterinarians in the same district were analyzed serologically by RBPT, SAT and ELISA. Of the cattle sera analyzed, 134 (32.92\%) and 
141 (34.64\%) were determined as positive by RBPT and SAT, respectively. Thirty-two (13\%), 35 (14.22\%) and 44 $(17.88 \%)$ of the farmers' sera were found positive for brucellosis by RBPT, SAT and ELISA, respectively. There was no significant difference between sexes for Brucella seropositivity. Of the 28 sera from veterinarians, 13 $(46.42 \%)$ were positive by the three serological tests. The high prevalence of brucellosis both in cattle and humans suggests that brucellosis is common in this area [47].

\section{European Union}

Bovine brucellosis, caused by B. abortus, is a significant problem for both public and animal health in Turkey. A study was conducted on the calving seasons between 2001 and 2006. A total of 626 serum samples of cattle obtained from 27 herds with a history of abortions was examined for Brucella antibodies by RBPT, SAT and ELISA. Of the cattle sera analyzed, $221(35.30 \%)$ and $206(32.92 \%)$ and 247 $(39.45 \%)$ were found to be positive by RBPT, SAT and ELISA, respectively. B. abortus was isolated from 48 (32.21\%) of 149 lung samples and stomach contents of the aborted fetuses. Based on the biochemical tests and the agglutination tests with monospecific $\mathrm{A}$ and $\mathrm{M}$ antisera, only 3 of the isolates were found to be B. abortus biotype 1 and the remaining 45 were biotype 3 . This study also revealed that the dominant biotype of $B$. abortus was biotype 3 in this region [48].

Austria, Denmark, Finland, Germany, the Province Bolzano (Italy), Luxembourg, Sweden, The Netherlands and Great Britain gained the status of an officially brucellosis free $(\mathrm{OBF})$ Member State or Region of a Member State (Decision 99/466/EC). According to Decision 66/94/COL, Norway has also reached the OBF status. In most of the nonOBF countries (France, Greece, Ireland, Italy, Portugal and Spain), eradication programs for bovine brucellosis approved for European co-financing were carried out in 2000. The official bovine brucellosis status in the European Union and Norway, at the end of Year 2000 [49].

In the OBF Member States, no positive herds were reported to be present at the end of the year. However, in Austria, one herd was found brucellosis positive during the year 2000 testing program. Germany reported two herds being infected. In all the other OBF countries, no positive herds were reported. In The Netherlands, none of the animals, that were classified positive by serological tests, were eventually confirmed to be truly infected (i.e. culture positive). No abortions due to brucellosis were reported in these countries. Austria and Great Britain have slaughtered some positive animals. No seropositive animal was detected in the context of pre-movement testing, artificial insemination stations testing programs or epidemiosurveillance in farms at risk in Finland, Luxembourg, Great Britain and Norway [49].

The epidemiological situation in non-OBF countries is extremely diverse. The situation in Belgium and France remained favorable in 2000. In Belgium, for example, the incidence of bovine brucellosis has been continuously decreasing over the last few years (about 500 infected herds identified in 1988-1989, less than 100 in 1993, 27 in 1996, 6 in 1997, 5 in 1998 and 2 in 1999). A total of four infected herds were detected in Belgium in 2000, among which two resulted from the importation of infected animals from Portugal. These herds were depopulated so that at the end of the year, no more infected cattle remained and 50,643 herds $(99.96 \%)$ with $3,009,133$ animals $(99.95 \%)$ were officially free of brucellosis. In the other non-OBF countries, the percentage of infected herds ranged from $0.12 \%$ (Ireland) to $1.31 \%$ (Italy). As far as data were available and reliable, a decreasing tendency in most countries was observed. The percentage of herds recognized OBF ranged from $49.9 \%$ (Portugal) to $97.7 \%$ (Ireland). Regional differences were obvious for the mainland of Portugal, the Azores and Madeira. In Italy, about $84 \%$ of the herds were recognized OBF in 1999, but no numbers were available for 2000. Where bacteriological examinations took place, B. abortus and $B$. melitensis have been isolated from cattle. $B$. melitensis is regularly isolated from cattle in contact with infected sheep and goats [49]. Bulgaria is an area free from Brucella strains (B. melitensis, B. suis and B. abortus) highly pathogenic for humans [50].

Bovine brucellosis was first reported in the Azores in 1947 and official program for disease control started in 1950, being reinforced in 1994 through an EU co-financed eradication program. By 2000, bovine brucellosis had been eradicated in four islands (Corvo, Flores, Graciosa and Pico) and reached a very low prevalence in Faial and Santa Maria. However, brucellosis was still present in the three remaining islands (Terceira, S. Miguel and S. Jorge). In the Azores, vaccination against bovine brucellosis started in 1968. The S19 vaccine was used until 1984 and was then replaced by Strain 45/20, which was used until 1999 . Due to the very low animal prevalence rate reached in each of the islands $(<1 \%)$, vaccination was then stopped. However, 3-4 years later, depending on the island, levels of infection increased dramatically and a new vaccination scheme, using the RB51 vaccine was considered. The general trend observed in the 3 islands is the clear decrease of the mean number of positive animals per herd, and mean disease prevalence and incidence. Terceira showed an initial within-herd prevalence rate close to $30 \%$ and the highest herd prevalence rate (close to $11 \%$ ) of the archipelago. Where almost all the cattle population was covered by mass vaccination and by MRT surveillance during the duration of the study, a regular and dramatic reduction of the herd and animal prevalence were observed. In S. Jorge, where the initial within-herd prevalence rate was high $(33 \%)$ although the initial herd prevalence rate was lower than in Terceira $(6 \%)$, a remarkable reduction in prevalence was observed only after 5 years. In S. Miguel, where the initial within-herd prevalence rate was similar to that on Terceira (about 30\%), no clear reduction in the prevalence rates were achieved until 2007 [51].

The incidence of brucellosis in cattle located at Republic of Macedonia is not as significant as it is in sheep and goats. The number of positive cattle is rather small, but the number of positive reactors has been increasing in recent years. In 1999, a total of 26,770 cattle were tested of which 47 animals were positive. In 2000, 54,361 animals were tested and 111 were found to have specific Brucella antibodies. The increase in the number of positive animals continued into 2001 as 81,486 cattle were tested and 243 found to be positive. Cattle were tested in 536 villages and 39 of them $(5.36 \%)$ had brucellosis positive. The animals principally 
affected in Greece are sheep, goats and cows. Sheep, goats and free ranging cows are infected by $B$. melitensis, however, cows kept indoors are also infected by B. abortus [52].

\section{Brucella Melitensis}

B. melitensis is a facultative intracellular bacterial pathogen that causes abortion in goats and sheep and Malta fever in humans. B. melitensis mainly causes abortions, stillbirths and the birth of weak offspring. Animals that abort may retain the placenta. Sheep and goats usually abort only once, but reinvasion of the uterus and shedding of organisms can occur during subsequent pregnancies Milk yield is significantly reduced in animals that abort, as well as in animals whose udder becomes infected after a normal birth. However, clinical signs of mastitis are uncommon. Acute orchitis and epididymitis can occur in males, and may result in infertility. Arthritis is seen occasionally in both sexes. Many non-pregnant sheep and goats remain asymptomatic [53].

\section{North America}

In some areas of the world, B. melitensis has become endemic in cattle populations. Although extremely rare in the United States, B. melitensis was isolated from a cow in southern Texas in 1999. Previously, B. melitensis was last detected in sheep and goats in southern Texas in 1969. Limited data are currently available on vaccines to protect cattle against $B$. melitensis. Currently, the World Organization for Animal Health, formerly known as the Office International des Epizooties, does not recommend the use of the B. melitensis Rev.1 vaccine in cattle. Data to support the use of other vaccines in protecting cattle against B. melitensis are currently unavailable [14].

In Michoacán, region of Mexico, blood samples were collected from 5114 animals from 79 herds. Sera were tested for antibodies against $B$. melitensis using the Rose Bengal plate test and the complement-fixation test. Information regarding the herds and each animal sampled were recorded through a personal interview at the farm. It was used random-effects multivariable logistic regression to analyze our data. Fifty-six herds of the 79 tested had at least one seropositive animal. The animal-level true seroprevalence was 9.8\% (CI=8.8, 10.7). Animals in large herds $(>34$ animals), in herds with high stock density $\left(>3.5\right.$ animals $\left./ \mathrm{m}^{2}\right)$ or animals $>24$ months old had higher odds of seropositivity (2.0, 1.7 and 1.8 , respectively) than those in small herds, in herds with low stock density or animals $<$ or $=24$ months old [54].

\section{South America}

In a retrospective analysis involving 1933 samples, 1377 strains of Brucella spp. were isolated in South America between 1968 and 1991 from humans and animals; $B$. melitensis was the most frequently isolated species from humans, followed by B. suis and B. abortus. B. melitensis 1 was the main biovar isolated in the period. Among the 367 strains isolated from humans in Argentina during 1994 2006, 145 B. melitensis isolated were biovar 1 (93,1\%), followed by biovar 1a $(4,8 \%)$, biovar $3(1,4 \%)$ and biovar $2 \mathrm{a}$ $(0,7 \%)$, based on differences in the quantitative distribution of the ' $A$ ' and ' $M$ ' antigens [55]. As expected pigs and goats were infected mainly with $B$. suis and $B$. melitensis respectively and sheep with $B$. ovis. However, $B$. suis, $B$. melitensis and $B$. abortus were also found in sheep, probably because of cross-contamination between animal species due to farming practices where continuous contact among the herds exists.

A study was conducted to characterize manifestation of B. melitensis in Peru. From January 1981 to June 1986, 39 families with 232 individuals were evaluated. Brucellosis was diagnosed in 118 family members (attack rate of $50,9 \%$ ). A lower attack rate was observed in children less than 10 years old compared with other age groups. Complete clinical data were available in 92 of the 118 affected members. Moderate and severe forms of the diseases were more prevalent in women than in men $(41.8 \% \mathrm{v} 13.5 \%)$. Twenty eight of the 92 patients developed some complications; articular involvement was the most prevalent $(23,9 \%)$. Arthritis was also more common in women than in men $(34,5 \% \mathrm{v} 8.1 \%)$. Overall, the following pattern was observed: peripheral arthritis $(54,5 \%)$; unilateral sacroiliitis $(23 \%)$; mixed arthritis $(4,5 \%)$, and spondylitis $(9,1 \%)$. Spondylitis was seen only in the elderly with chronic brucellosis. Four patients developed extra-articular rheumatism. Within members of family groups, arthritis occurred less frequently than in individual patients from the same hospital [56].

Although several outbreaks of $B$. melitensis infection have been reported among laboratory workers or goat cheese consumers, outbreaks related to rural labor have been rarely studied. An outbreak of human brucellosis among farm workers of Argentina was studied and revealed a close relationship with an epidemic of caprine abortions which occurred shortly before on the same farm. High rates of $B$. melitensis infection were found among goats. Active brucellosis was diagnosed in 33 subjects (14 with positive blood culture for $B$. melitensis), while other 27 did not show evidence of illness. While 25 of the brucellosis active patients were rural workers, only 5 of the healthy subjects were engaged in rural labor. Active brucellosis was diagnosed in $91,3 \%$ of the subjects in continuous contact with goats and in $32 \%$ of those having an occasional contact with the animals. All the 60 subjects denied consumption of goat cheese or milk. As shown here, epidemic human infections by $B$. melitensis may develop among people frequently in contact with infected goat herds or goat manure [57].

\section{Near East Region}

Brucellosis is endemic among ruminants in the Nile Delta region of Egypt. In this region the practice of throwing animal waste into Nile canals is common. As a result, water can be contaminated with potential zoonotic pathogens such as B. melitensis that could infect fish. Results $9.2 \%$ and $8.3 \%$ of serum samples from Nile catfish were positive by Rose Bengal Test and Rivanol Test, respectively. B. melitensis biovar 3 was isolated from $5.8 \%, 4.2 \%, 5.8 \%$ and $13.3 \%$ of liver, kidney and spleen samples and skin swabs, respectively. To our knowledge this is the first report of isolation of $B$. melitensis biovar 3 from fresh water fish [58].

In countries of the Near East region, brucellosis was reported in almost all domestic animals, particularly cattle, 
sheep and goats. Brucellosis in camels has been reported in Saudi Arabia, Kuwait, Oman, Iraq, Iran, Sudan, Egypt, Libya and Somalia. It has been reported even in racing camels in the United Arab Emirates. In Egypt, brucellosis has been reported also in buffaloes, equines and swine. $B$. melitensis biovar 3 is the most commonly isolated species from animals in Egypt, Jordan, Israel, Tunisia and Turkey. $B$. melitensis biovar 2 was reported in Turkey and Saudi Arabia, and B. melitensis biovar 1 in Libya, Oman and Israel [59].

Prevalence of a serologic reaction in Egypt was 4.98\% for cattle, $3.52 \%$ for buffaloes, $4.8 \%$ for sheep, and $2.19 \%$ for goats by the Rose Bengal plate test. Prevalence of a serologic reaction was $4.73 \%$ for cattle, $3.44 \%$ for buffaloes, $4.8 \%$ for sheep, and $2.19 \%$ for goats by the standard tube agglutination test. Prevalence of a serologic reaction was $4.48 \%$ for cattle, $3.37 \%$ for buffaloes, $4.8 \%$ for sheep, and $2.19 \%$ for goats by the Rivanol test. The highest prevalence for cattle, buffaloes, sheep, and goats by any of the 4 tests was in Benisuef, except for the BAPA test in goats, which showed highest prevalence rates in Monofia. Isolation of the causative agent is still the standard diagnostic method for brucellosis. Thus, for definitive and confirmative diagnosis of serologically reactive animals, bacteriologic isolation and identification of Brucella spp. were performed. A total of 47 isolates of Brucella spp. were identified; all isolates were $B$. melitensis biovar 3. Isolation of Brucella spp. confirmed active brucellosis in the animals tested. A Brucella spp. was also isolated from milk samples from serologically nonreactive buffaloes in Benisuef [60].

\section{European Union}

On the basis of the provisions of Directive 91/68/EEC, nine Member States are recognized officially brucellosis frees (ObmF) (B. melitensis): Belgium, Denmark, Finland, Germany, The Netherlands, Ireland, Luxembourg, Sweden and the United Kingdom. Additionally, in two Member States (France, Spain) some regions have reached this status (Decision 93/52/EEC). In these countries, an annual monitoring program is carried out in accordance with requirements of Directive $91 / 68 / \mathrm{EC}$ to confirm the freedom from B. melitensis. Norway is OmbF according to the EFTA surveillance authority's Decision 97/232/EC. In 2000, still in four Member States, no region did reach the OmbF status: Greece, Italy, Portugal and Austria (that got the ObmF status in 2001). As far as information is available, no cases of infected holdings were reported in the $\mathrm{OmbF}$ (B. melitensis) Member States. However, in Belgium, for example, 11 samples out of the $6536(0.17 \%)$ were found positive by the ELISA, but none of these sera was found positive by RB and CFT. In Austria, no cases of ovine and caprine brucellosis were notified [49]. During 2000, approved European cofinanced eradication programs for ovine and caprine brucellosis were implemented in France, Greece, Italy, Portugal, and Spain.

Small ruminants in Macedonia, brucellosis is continuing problem and remains one of the most important reservoirs of the disease. In 1999 and 2000, a total of 381,142 sheep and 670,963 and goats were tested. There were 2197 and 2124 positive sheep and goats, respectively, In 2001, a total of 663,350 sheep were tested in 914 villages. Positive sheep were found in 134 villages $(14.66 \%)$ and a total of 3738 animals were found positive $(0.56 \%)$. In goats, brucellosis was found in 799 animals of 71,188 tested (1.22\%). Goats were found positive in $48(9.01 \%)$ out of 533 tested villages [50].

Regarding the incidence of brucellosis among sheep and goats on the Greek islands, in 1999, 2664 herds were examined (a total of 156,788 animals) and 67 of them were positive (854 animals). In 2000, 5249 herds were examined (a total of 260,633 animals) and 98 of them were positive (961 animals) [50].

\section{China}

Based on the analysis of 3000 Brucella strains isolated before $1980,65 \%$ is for B. melitensis, between the 1980 's and 1990's, 2000 strains of Brucella were isolated and 30\% were for B. melitensis and from 1990 to 1998,300 strains of Brucella were isolated and $80 \%$ is for B. melitensis [61].

\section{Brucella Ovis}

B. ovis affects sheep but not goats. This organism can cause epididymitis, orchitis and impaired fertility in rams. Initially, only poor quality semen may be seen; later, lesions may be palpable in the epididymis and scrotum. Epididymitis may be unilateral or, occasionally, bilateral. The testes may atrophy. Some rams shed B. ovis for long periods without clinically apparent lesions. Abortions, placentitis and perinatal mortality can be seen in ewes but are uncommon. Systemic signs are rare [62].

\section{North America}

Serological evidence was found 1974 and the organism was isolated and confirmed in Mexico in 1979; it was related imported to Suffolk rams imported from the US. The National Program for the eradication of this disease was initiated in 1990s, thus, there is not enough information on the incidence of $B$. ovis. However, in some isolated studies, a very high prevalence of $9 \%$ was found in some flocks in central Mexico. Recently, sheep ranchers have become aware of this disease because of an increase in the rates positives in serological tests [62]. It is now mandatory that every male older than 8 months be tested. The official test is a double immunodiffusion using hot saline extract of the Brucella spp. as the antigen. All positive animals have to be castrated and killed.

A study was conducted to estimate the seroprevalence of B. ovis infection in rams in the Estrie and Bas-Saint-Laurent regions (Quebec). Rams sera $(n=258)$ were serologically evaluated from 224 rams in 30 commercial flocks and from 34 rams at 2 slaughterhouses by using an enzyme linked immunosorbent assay. Epididymides and testes were examined by palpation on farms and microscopically for culled rams. No ram was seropositive to $B$. ovis or had lesions suggestive of brucellosis from the farm or slaughterhouse surveys [63].

\section{European Union}

One study was conduct to investigate $B$. ovis infection in sheep during 2002 and 2003 in Croatia [62]. A total of 30,635 sheep blood samples were examined using the enzyme-linked immunosorbent assay (ELISA). In 2002, 1014 out of 14,404 examined sheep blood samples $(7 \%)$ from six counties gave positive reactions while 2060 
(14.3\%) were found suspicious. In 2003, 638 out of 16,221 examined sheep blood samples in nine counties $(3.9 \%)$ tested positive while $1083(6.7 \%)$ were suspicious. In rams and sheep that were serologically positive specific pathological changes were found in $68(43.6 \%)$ out of 156 examined rams and in $5(3.8 \%)$ out of 133 examined sheep. B. ovis was isolated from ram tissues from three counties and identified with classical microbiological procedures and the polymerase chain reaction (PCR). This research proves that $B$. ovis is present in sheep flocks in Croatia which is also the first proof of its existence in the country [64].

\section{Brucella Suis}

In pigs, the most common symptom is abortion, which can occur at any time during gestation, and weak or stillborn piglets. Vaginal discharge is often minimal and abortions may be mistaken for infertility. Occasionally, some sows develop metritis. Temporary or permanent orchitis can be seen in boars. Boars can also excrete $B$. suis asymptomatically in the semen and sterility may be the only sign of infection. Swollen joints and tendon sheaths, accompanied by lameness and incoordination, can occur in both sexes. Less common signs include posterior paralysis, spondylitis and abscesses in various organs. Although some pigs recover, others remain permanently infected. Fertility can be permanently impaired, particularly in boars. Some animals remain asymptomatic [65].

In hares, B. suis biovar 2 infection is characterized by nodules in the internal organs, particularly the reproductive organs, as well as the subcutaneous tissues and muscles. The nodules can become purulent. The animal's body condition may be minimally affected. In caribou and reindeer, B. suis biovar 4 can cause abortion and retained placenta. Metritis and mastitis can also occur. Males may develop orchitis. Lameness can occur in both sexes from arthritis, bursitis, tenosynovitis and/ or hygromas. Subcutaneous abscesses are also seen [49].

\section{North America}

Two hundred twenty seven adult ( $>8 \mathrm{mo}$ ) feral swine (Sus scrofa) trapped from April through July 1999 at three locations on a coastal South Carolina (USA) peninsula with restricted ingress and egress were tested for B. suis and pseudorabies virus (PRV) antibodies. Approximately $44 \%$ of the animals tested positive for B. suis antibodies and $61 \%$ tested positive for antibodies to PRV. Previous surveys (1976 and 1992) of feral swine at the same location with similar methods indicated lower seroprevalences $(28 \%$ and $18 \%$ for B. suis and $0 \%$ and $19 \%$ for PRV). We also found $39 \%$ of feral swine seropositive $(\mathrm{n}=179)$ for Trichinella spiralis and $49 \%$ seropositive $(\mathrm{n}=181)$ for Toxoplasma gondii. Results of repeated sampling demonstrated that seroprevalence to pathogens can increase with time in an isolated, unhunted population of feral swine suggesting an increased risk to local domestic livestock [65].

Feral swine are rapidly expanding their ranges across the United States, with at least 44 of 50 states reporting populations. Feral swine populations were estimated at 4 million animals in 1999 by one report, whereas another report estimated in 2000 that Texas alone had 3 million. In at least 14 states, brucellosis has been documented to be present in feral swine populations, with some populations demonstrating high seroprevalence. Feral swine shed $B$. suis for extended periods of time in urine and mucosal secretions. Numerous field cases have been documented in which cattle were infected with $B$. suis from feral swine. Cattle infected with $B$. suis have positive responses on brucellosis serologic tests, which cannot be differentiated from responses after $B$. abortus infection [14].

\section{European Union}

Brucellosis caused by B. suis biovar 2 is frequently reported in the Eurasian wild boar (Sus scrofa) and the European brown hare (Lepus europaeus), and apparent prevalence ranging from 8 to $32 \%$ has been reported in wild boar in the EU [66]. The pathogenicity for humans of B. suis biovars 1, 3 and 4 is well established, whereas $B$. suis biovar 2 seems to be less pathogenic. Indeed, although hunters and pig farmers have repeatedly experienced infectious contact with $B$. suis biovar 2 (found in wild boar and outdoor-rearing pigs in Europe), isolation of B. suis biovar 2 from human samples have only been seldom reported [67]. As shown, brucellosis in swine has re-emerged as a result of spillover from the wild boar brucellosis (B. suis biovar 2) reservoir, particularly in outdoor reared pigs. Wild animals are often at risk as a consequence of contacts with infected livestock, particularly in extensive breeding systems.

In all EU countries and Norway, boars are subject to preentry testing and regular control every 18 months at the artificial insemination stations as well as before leaving the station in case of exhibitions, auctions or trade. Breeding pigs and other animals are examined serologically for export in Belgium, The Netherlands and Norway. In Norway, boars are also tested serologically prior to import. In Belgium, 11 samples out of $6536(0.17 \%)$ were found positive by the ELISA, but none of these sera was found positive by RB and CFT during 2000. B. suis has not been reported in pigs in Belgium since 1969, in The Netherlands since 1973, and never in Finland, Sweden, the United Kingdom and Norway.

In Germany, one outbreak of porcine brucellosis was notified and $B$. suis biovar 2 was isolated in pigs and wild boars. In France, seven outbreaks of swine brucellosis were reported in 2000 after isolation of B. suis biovar 2. Pig herds involved in these outbreaks were all outdoor herds. An epidemiological link with wild boars infected by $B$. suis biovar 2 is strongly suspected. In Denmark, swine brucellosis has not been detected since 1999, when one case of $B$. suis biovar 2 occurred in a free-ranging pig herd. This was last seen in 1994 in another free-ranging pig herd in the same area, where $B$. suis biovar 2 was also detected in wild hares. The persistence of pathogenic Brucella spp. in domestic livestock or free-ranging wildlife remains unresolved, despite decades of regulatory efforts worldwide.

In 2001, antibodies to Brucella spp. were detected in the wild boar (Sus scrofa) population of Regional Park in the Piedmont, northwest Italy. This was the first report of swine brucellosis in Italian wildlife. In total, 2,267 serum samples and 1,841 tissue samples were collected and tested from 2001 to 2007. Data confirm the presence of B. suis 2 in wild boar in Italy, the prevalence based on serology was $19.8 \%$ and culture 10.8\%. Annual prevalence estimates (antibodies and culture) suggest that B. suis 2 was maintained in this 
population from 2001 to 2004 at a relatively constant level. In 2005 and 2006, prevalence significantly decreased, and in 2007, it returned to previous 2001-2004 levels [66].

In Austria, Germany, Portugal and Spain swine brucellosis has also been reported [49]. Between the years 2000 and 2004, 93,107 sera from 1.997 pig herds in 11 regions of Croatia were tested for the presence of antibodies against brucellosis. Positive results were observed in 67 herds from seven regions (mean individual prevalence: approximately $1 \%$; herd prevalence: $3.4 \%$ ). The herds from all but two of the infected farms were reared outdoors and thus almost certainly came into contact with wildlife. From 2003 to 2004, 424 sera, which were randomly collected from hunted wild boar (Sus scrofa), were also tested and shown to have a mean seroprevalence of $27.6 \%$. Brucella was isolated from 88 out of 151 serologically positive pigs $(58.3 \%)$ and 7 of the $93(7.5 \%)$ wild boar which were randomly submitted for bacteriological study. All but three isolates were B. suis biovar 2; the others being biovar 3 . These results suggest that brucellosis is enzootic in Croatian populations of wild boar. These populations represent a potential disease reservoir for free-range pig farms, as they do in other countries of Central and Western Europe. This is the first report of $B$. suis biovar 3 in swine and wild boar in Europe, which is an issue of serious concern for public health [68].

During two survey rounds of a national surveillance system for infectious diseases in wild boar in Switzerland between 2001 and 2003, 1949 blood samples were collected from hunted wild boar. Brucellosis due to B. suis biovar 2 was confirmed serologically and by bacterial isolation [69].

In a study conduct in the Iberian Peninsula, high apparent prevalence brucellosis was found (33\%; 95\% CI 31.6 - 34.4). The highest apparent prevalence was in average $46 \%$ with some populations reaching over $80 \%$. The remaining areas showed lower but still high values, $26 \%$ in average. In strong contrast with the situation in wild ruminants, the wild boar population was found seriously affected by $B$. suis biovar 2 infection. Historical contact between free ranging Iberian domestic pigs and wild boar could have boosted wild boar infection with B. suis biovar 2 in the Iberian Peninsula [70].

\section{Brucella Canis}

B. canis can cause abortions and stillbirths in pregnant dogs. Most abortions occur late, particularly during the seventh to ninth week of gestation. Abortions are usually followed by a mucoid, serosanguinous or gray-green vaginal discharge that persists for up to six weeks. Early embryonic deaths and resorption have been reported a few weeks after mating, and may be mistaken for failure to conceive. Some pups are born live but weak; most die soon after birth. Other congenitally infected pups can be born normal and later develop brucellosis. Clinical signs occur during subsequent pregnancies in some dogs, but not in others. Epididymitis, scrotal edema, orchitis and poor sperm quality may be seen in males. Scrotal dermatitis can occur due to self-trauma. Unilateral or bilateral testicular atrophy can be seen in chronic infections, and some males become infertile [51].

Lymphadenitis is common in infected dogs. Lethargy or fatigue, exercise intolerance, decreased appetite, weight loss and behavioral abnormalities (loss of alertness, poor performance of tasks) are occasionally reported; however, most affected dogs do not appear seriously ill. Occasionally, discospondylitis of the thoracic and/or lumbar vertebrae can cause stiffness, lameness or back pain. Uveitis, endophthalmitis, polygranulomatous dermatitis, endocarditis and meningoencephalitis have also been reported. Fever is uncommon, and deaths are rare except in the fetus or newborn. Many infected dogs remain asymptomatic [51].

\section{Brucellosis in Marine Mammals}

There is little information on the effects of brucellosis in marine mammals. Reproductive disease is difficult to assess in wild animals, but Brucella has been isolated from the reproductive organs of some marine species. In rare cases, infections have also been linked to lesions or clinical disease. Brucella-associated abortions and placentitis were reported in two captive bottlenose dolphins. Lesions consistent with a possible abortion were also reported in a wild Atlantic whitesided dolphin. Recently, Brucella was isolated from a dead newborn Maui's dolphin in New Zealand; the animal was born alive but died before taking its first breath. Brucellaassociated epididymitis has been reported in porpoises, and orchitis from suspected brucellosis was reported in minke whales [71].

Brucella infections have been linked with systemic disease in a few marine mammals. Brucella-associated meningoencephalitis was reported in three stranded striped dolphins. Other signs of Brucella-associated systemic disease have been seen mainly in Atlantic white-sided dolphins; the lesions included hepatic and splenic necrosis, lymphadenitis and mastitis. Brucella has also been identified as a possible secondary invader or opportunistic pathogen in debilitated seals, dolphins and porpoises. It has been isolated from several subcutaneous abscesses. In addition, this organism has been found in organs with no microscopic or gross lesions, and in apparently healthy animals [71].

\section{REFERENCES}

[1] Young EJ. An overview of human brucellosis. Clin Infect Dis 1995; 2: 283-90.

[2] OIE, Terrestrial Animal Health Code Brucellosis, http://www.oie.int/ (2009), [consulted in 2 March, 2010].

[3] Foster G, Osterman BS, Godfroid J, et al. Brucella ceti sp. nov. and Brucella pinnipedialis sp. nov. for Brucella strains with cetaceans and seals as their preferred hosts. Int J Syst Evol Microbiol 2007; 57: 2688-93.

[4] Scholz HC, Hubalek Z, Nesvadbova J, et al. Isolation of Brucella microti from soil. Emerg Infect Dis 2008; 14: 1316-7.

[5] Corbel MJ. Brucellosis: an overview. Emerg Infect Dis 1997; 3: 213-21.

[6] Maloney GE, Fraser WR. CBRNE - Brucellosis. Omaha, Nebraska, eMedicine, 2004 (http://www.emedicine.com/emerg/topic883.htm accessed 1 October 2006).

[7] Abdou AE. Fifty years of veterinary public health activities in the Eastern Mediterranean Region. East Mediter Health J 2000; 6: 796807.

[8] Hoover DL, Friedlander AM. Brucellosis. In: Zajtchuk R, Ed. Textbook of military medicine: medical aspects of chemical and biological warfare. Washington DC, US Department of the Army: Surgeon General \& Borden Institute 1997; vol. 2: pp. 513-21.

[9] Hartigan P. Human brucellosis: epidemiology and clinical manifestations. Ir Vet J 1997; 50: 179-80.

[10] Jimenez de Bagues MP, Marin C, Blasco JM. Effect of antibiotic therapy and strain 19 vaccination on the spread of Brucella melitensis within an infected dairy herd. Prev Vet Med 1991; 11: $17-24$. 
[11] Verger JM. B. melitensis infection in cattle. Brucella melitensi. In: Plommet \& Vergers, Eds. Martinus Nijhoff Publ.: DordrechtBoston-Lancaster 1985

[12] Ewalt DR, Payeur JB, Rhyan JC, et al. Brucella suis biovar 1 in naturally infected cattle: a bacteriological, serological, and histological study. J Vet Diagn Invest 1997; 10: 417-20.

[13] Ragan V. The Animal and Plant Health Inspection Service (APHIS): Brucellosis eradication program in the Unites States. Vet Microbiol 2002; 90: 11-8.

[14] Donch DA, Gertonson AA. Status Report - Fiscal Year 2008. USDA APHIS Veterinary Services, Cooperative State-Federal Brucellosis Eradication Program, 2008. Accessed in: 04/07/10. http://www.aphis.usda.gov/animal_health/animal_diseases/brucello sis/

[15] Olsen S, Tatum F. Bovine Brucellosis. Veterinary clinics of North America. Food Anim Pract 2010; 26: 15-27.

[16] Ebel ED, Williams MS, Tomlinson SM. Estimating herd prevalence of bovine brucellosis in 46 USA states using slaughter surveillance. Prev Vet Med 2008; 85: 295-316.

[17] Gurría TFJ. Importancia de la Erradicación de la Brucelosis en México. Conferencia Magistral. In: Luna-Martínez JE, Suárez GF, Eds. III Foro Nacional de Brucelosis. Memorias. SAGAR, CONASAG, FMVZ, UNAM, OPS, México 1998.

[18] Luna-Martínez JE, Mejía-Terán C. Brucellosis in Mexico: current status and trends. Vet Microbiol 202; 90: 19-30.

[19] DTBB, (Dirección de Tuberculosis Bovina y Brucelosis). Informe Anual 2000. Resultados Preliminares. CANETB, DGSA, CONASAG, SAGAR, Coyoacán, D.F. 2000.

[20] López-Merino A. Brucellosis in Latin America. In: Young EJ, Corbel MJ, Eds. Brucellosis clinical and laboratory aspects. Boca Raton: CRC Press 1989; pp. 151-61.

[21] Moreno E. Brucellosis in Central America. Vet Microbiol 2002; 90: $31-8$.

[22] Contreras JA. Brucelosis en Enfermedades de los Bovinos, Diagnóstico, Tratamiento y Control, Segunda Edición. Barquisimeto: Venezuela 2000; pp. 475-89.

[23] Lord VJ, Cherwonogrodzky J, Schurig G, et al. Venezuelan field trials of vaccines against brucellosis in swine. Am J Vet Res 1998; 59: 546-51.

[24] Vargas OFJ. Brucellosis in Venezuela. Vet Microbiol 2002; 90: 3944.

[25] Instituto Nacional de Estadísticas, 1998. VI Censo Agropecuario Nacional. Chile, INE-ODEPA. Santiago, Chile 1997.

[26] Rivera SA, Ramírez MC, Popetegui IP. Eradication of bovine brucellosis in the 10th Region de Los Lagos, Chile. Vet Microbiol 2002; 90: 45-53

[27] Baumgarten D. Brucellosis: a short review of the disease situation in Paraguay. Vet Microbiol 2002; 90: 63-9.

[28] Carrillo CG. Animal and human brucellosis in the Americas. Off Int Epizooties 1990; 4-30.

[29] Samartino LE. Brucellosis in Argentina. Vet Microbiol 2002; 90: 71-80.

[30] Poester F, Figueiredo VCF, Lôbo JR, et al. Prevalence studies on bovine brucelosis according to Brazilian National Program for the control and eradication of bovine brucellosis and tuberculosis: Introduction. Arq Bras Med Vet Zootec 2009; 61 (1): 01-5.

[31] Gonçalves VSP, Ribeiro LA, Caldas RA, et al. Epidemiological status of bovine brucellosis in the Federal District, Brazil. Arq Bras Med Vet Zootec 2009; 61 (1): 14-8.

[32] Azevedo SS, Neto FJS, Dias RA, et al. Epidemiological situation of bovine brucellosis in the State of Espírito Santo, Brazil. Arq Bras Med Vet Zootec 2009; 61 (1): 19-26.

[33] Rocha WV, Gonçalves VSP, Coelho CG, et al. Epidemiological status of bovine brucellosis in the State of Goiás, Brazil. Arq Bras Med Vet Zootec 2009; 61 (1): 27-34.

[34] Negreiros RL, Dias RA, Ferreira F, et al. Epidemiologic situation of bovine brucellosis in the State of Mato Grosso, Brazil. Arq Bras Med Vet Zootec 2009; 61 (1): 56-65.

[35] Chate SC, Dias RA, Amaku M, et al. Epidemiological situation of bovine brucellosis in the State of Mato Grosso do Sul, Brazil. Arq Bras Med Vet Zootec 2009; 61 (1): 46-55.

[36] Gonçalves VSP, Delphino MKVC, Dias RA, et al. Epidemiological status of bovine brucellosis in the State of Minas Gerais, Brazil. Arq Bras Med Vet Zootec 2009; 61 (1): 35-45.
[37] Dias JA, Müller EE, Dias RA, et al. Epidemiological situation of bovine brucellosis in the State of Paraná, Brazil. Arq Arq Bras Med Vet Zootec 2009; 61 (1): 66-76.

[38] Marvulo MFV, Ferreira F, Dias RA, et al. Epidemiological situation of bovine brucellosis in the State of Rio Grande do Sul, Brazil. Arq Bras Med Vet Zootec 2009; 61 (1): 93-102.

[39] Alves AJS, Gonçalves VSP, Figueiredo VCF, et al. Epidemiological situation of bovine brucellosis in the State of Bahia, Brazil. Arq Bras Med Vet Zootec 2009; 61 (1): 6-13.

[40] Ogata RA, Gonçalves VSP, Figueiredo VCF, et al. Epidemiological situation of bovine brucellosis in the State of Tocantins, Brazil. Arq Bras Med Vet Zootec 2009; 61 (1): 126-34.

[41] Silva VGSO, Dias RA, Ferreira F, et al. Epidemiological situation of bovine brucellosis in the State of Sergipe, Brazil. Arq Bras Med Vet Zootec 2009; 61 (1): 109-117.

[42] Dias RA, Gonçalves VSP, Figueiredo VCF, et al. Epidemiological situation of bovine brucellosis in the State of São Paulo, Brazil. Arq Bras Med Vet Zootec 2009; 61 (1): 118-125.

[43] Sikusawa S, Amaku M, Dias RA, et al. Epidemiological situation of bovine brucellosis in the State of Santa Catarina, Brazil. Arq Bras Med Vet Zootec 2009; 61 (1): 103-8.

[44] Villar KS, Amaku M, Dias RA, et al. Epidemiological situation of bovine brucellosis in the State of Rondônia, Brazil. Arq Bras Med Vet Zootec 2009; 61 (1): 85-92.

[45] Klein-Gunnewiek MFC, Amaku M, Dias RA, et al. Epidemiological situation of bovine brucellosis in the State of Rio de Janeiro, Brazil. Arq Bras Med Vet Zootec 2009; 61 (1): 77-84.

[46] FAO/WHO/OIE, Round Table on the Use of Rev.1 Vaccine in Small Ruminants and Cattle. CNEVA Alfort: France 1995; pp. 212.

[47] Otlu S, Sahin M, Atabay I, et al. Sorological investigations of Brucellosis in cattle, farmers and veterinarians in the kars district of Turkey. Acta Vet BRNO 2008; 77: 117-21.

[48] Sahin M, Genç O, Unver A, et al. Investigation of bovine brucellosis in the Northeastern Turkey. Trop Anim Health Prod 2008; 40: 281-6.

[49] Godfroid J, Käsbohrer A. Brucellosis in the European Union and Norway at the turn of the twenty-first century. Vet Microbiol 2002; 90: $135-45$.

[50] Gcheva N, Kojuharova M, Vladimirova N, et al. Infectious diseases in Bulgaria for 1999. Analysis of the main epidemiological features. Inf J 2001; 4: 5-40.

[51] Martins H, Garin-Bastuji B, Lima F, et al. Eradication of bovine brucellosis in the Azores, Portugal-Outcome of a 5-year programme (2002-2007) based on test-and-slaughter and RB51 vaccination. Prev Vet Med 2009; 90: 80-9.

[52] Taleski V, Zerva L, Kantardjiev T, et al. An overview of the epidemiology and epizootology of brucellosis in selected countries of Central and Southeast Europe. Vet Microbiol 2002; 90: 147-55.

[53] DelVecchio VG, Kapatral V, Redkar RJ, et al. The genome sequence of the facultative intracellular pathogen Brucella melitensis. Proc Natl Acad Sci USA 2002; 99: 443-8.

[54] Solorio-Rivera JL, Segura-Correa JC, Sánchez-Gil LG. Seroprevalence of and risk factors for brucellosis of goats in herds of Michoacan, Mexico. Prev Vet Med 2007; 14: 282-90.

[55] Lucero NE, Ayala SM, Escobar GI, et al. Brucella isolated in humans and animals in Latin America from 1968 to 2006 Epidemiol Infect 2008; 136: 496-503.

[56] Gotuzzo E, Seas C, Guerra JG, et al. Brucellar arthritis: a study of 39 Peruvian families. Ann Rheum Dis 1987; 46: 506-9.

[57] Wallach JC, Samartino LE, Efron A, et al. Human infection by Brucella melitensis: an outbreak attributed to contact with infected goats. FEMS Immunol Med Microbiol 1997; 19: 315-21.

[58] El-Tras WF, Tayel AA, Eltholth MM, et al. Brucella infection in fresh water fish: Evidence for natural infection of Nile catfish, Clarias gariepinus, with Brucella melitensis. Vet Microbiol 2010; 141: 321-5.

[59] Refai M. Incidence and control of Brucellosis in the Near East region. Vet Microbiol 2002; 90: 81-110.

[60] Samaha H, Al-Rowaily M, Khoudair RM, et al. Multicenter Study of Brucellosis in Egypt. EID J Home 2008; 14(12): 1916-8.

[61] Deqiu S, Donglou X, Jiming Y. Epidemiology and control of Brucellosis in China. Vet Microbiol 2002; 90: 165-82.

[62] Méndez NG, Díaz AE, Morales AJF, et al. Epididimitis Ovina: Estudios bacteriológico y serológico. Vet Mex 1990; 30: 329-36. 
[63] Arsenault J, Girard C, Dubreuil P, et al. Lack of evidence of Brucella ovis infection in rams in Quebec. Can Vet J 2004; 45: 312-4.

[64] Spicić S, Marjanović S, Zdelar-Tuk M, et al. First evidence of Brucella ovis infection in Republic of Croatia. Dtsch Tierarztl Wochenschr 2009; 116: 209-13.

[65] Gresham CS, Gresham CA, Duffy MJ, et al. Increased prevalence of Brucella suis and pseudorabies virus antibodies in adults of an isolated feral swine population in coastal South Carolina. J Wildl Dis 2002; 38: 653-6.

[66] Bergagna S, Zoppi S, Ferroglio E, et al. Epidemiologic Survey for Brucella suis Biovar 2 in a Wild Boar (Sus scrofa) Population in Northwest Italy. J Wildl Dis 2009; 45: 1178-81.

[67] Godfroid J, Cloeckaert A, Liautard JP, et al. From the discovery of the Malta fever's agent to the discovery of a marine mammal reservoir, brucellosis has continuously been a re-emerging zoonosis. Vet Res 2005; 36: 313-26.

[68] Cvetnić Z, Spicić S, Toncić J, et al. Brucella suis infection in domestic pigs and wild boar in Croatia. Rev Sci Tech 2009; 28: 1057-67.

[69] Leuenberger R, Boujon P, Thür B, et al. Prevalence of classical swine fever, Aujeszky's disease and brucellosis in a population of wild boar in Switzerland. Vet Rec 2007; 160: 362-8.

[70] Muñoz PM, Boadella M, Arnal M, et al. Spatial distribution and risk factors of Brucellosis in Iberian wild ungulates. BMC Infect Dis 2010; 10: 46 .

[71] The Center for Food Security \& Public Health. Brucellosis in Marine Mammals. Iowa State University, July 28, 2009.

(C) Lopes et al.; Licensee Bentham Open.

This is an open access article licensed under the terms of the Creative Commons Attribution Non-Commercial License (http://creativecommons.org/licenses/by-nc/ $3.0 /$ ) which permits unrestricted, non-commercial use, distribution and reproduction in any medium, provided the work is properly cited. 